\title{
A DEMOGRAPHIC DECOMPOSITION OF ELDERLY LIVING ARRANGEMENTS WITH A MEXICAN EXAMPLE*
}

\begin{abstract}
Population trends in developing countries raise concern about support for the elderly. The proportion of elderly living with extended kin is an indicator of support. This paper considers the analytic utility of a demographic decomposition of living arrangements of elderly Mexicans into population components which include weights for age and marital composition and corresponding rates or propensities. Separate decompositions for elderly males and females demonstrate the importance of population composition to the makeup of the elderly population who are living with extended kin. The utility of the decomposition for comparative analysis is demonstrated by decomposing gender differences in living arrangements. The higher proportion of women living with extended kin is primarily the result of gender differences in age-specific marital status and only secondarily the results of actual differences in propensities toward this type of living arrangement. The utility and limitations of this analytic tool for comparative research are discussed.
\end{abstract}

Key Words: decomposition, demography, gender, living arrangements, Mexican

\section{INTRODUCTION}

Rapid growth in the numbers of Third World elderly, and projected increases in their proportion within the population of many less developed countries (LDCs) is turning the attention of demographers to the aging process in developing countries. A number of analysts have pointed to the need to learn more about the social conditions and living situation of the elderly in these countries (Binstock, Chow, and Schulz 1982; Treas and Logue 1986; Kinsella 1988; Tout 1989). Living arrangements is one facet of the elderly condition which is of interest to researchers and policy makers because it may be closely linked to the well-being of the elderly in many developing countries (Cowgill and Holmes 1972; Cowgill 1986; Kinsella 1988; Martin 1989; DeVos 1990). Recent availability of large sample survey data creates an opportunity for nationally representative investigations of living arrangements. As this type of data becomes increasingly available for LDCs, it is important to identify and evaluate analytic tools which might provide insights into the nature and variation of household living arrangements among the elderly. The objective of this paper is to propose a demographic decomposition of living arrangements, and to demonstrate its utility as an analytic tool for comparative analysis by decomposing gender differences in living arrangements of a nationally representative sample of elderly Mexicans. 


\section{RESEARCH ON ELDERLY LIVING ARRANGEMENTS IN LDCS}

Living arrangements focus on the composition of households in which individuals reside at different points in their lives. Population trends and differentials may impinge on living arrangements in ways that have implications for social welfare of the young and the old (Bongaarts 1983). Decline in fertility and family size, for instance, raises concerns about the shrinking base of kinship support for the elderly (Giele 1982). Gender difference in the need for family support has been linked to a tendency in many countries for more women to be living without a spouse as a result of marrying earlier, living longer and being less likely to remarry than their male counterparts (Kinsella 1988).

As a social indicator, living arrangements provide a summary measure of the family circumstances of the elderly at different times, places, or locations in the social structure of a society (Sweet 1978). With whom the elderly live indicates the residential dimension of their family life (Wall, Robin, and Laslett 1983) and is an important social context of their day to day lives (Kertzer 1986). Although living with children or other family members in an extended family does not guarantee the social welfare of the elderly, just as living apart does not preclude other familial relationships, researchers have noted that a common household does facilitate the sharing of resources (Bianchi 1981). This type of indicator seems particularly relevant in developing countries where the family is the major or only source of social support. Martin observes that, "Although family support can be given without living together, coresidence even under circumstances of good health and economic independence of the elderly is viewed as a form of insurance against future need" (1989:627).

The specific operationalization of living arrangements varies by the context of the research. In the United States, for instance, analysts often focus on the trend toward living alone. Martin (1989) uses a multiple classification scheme for examining living arrangements of Asian elderly which includes living alone, living with a spouse only, living with children, and living only with other relatives. Reflecting the concept of filial obligation, her classification scheme is particularly designed to recognize those cases in which the elderly are living with their own children. DeVos' (1990) research compares the extent to which the elderly in six Latin American countries live in extended family households. The decision to focus on extended family households is based on an earlier analysis (DeVos 1987) in which she demonstrates that inclusion of extended kin in the household is a common arrangement in Latin America.

Whereas empirical research on the living arrangements of the elderly in the United States is extensive (Wolf 1984; Wolf and Soldo 1988), the empirical basis for generalizations about the elderly in LDCs has been more limited. In Aging and Modernization, for instance, Cowgill and Holmes (1972) relied on a collection of ethnographics and community studies to support a set of broad generalizations according to which the relative status and social security of the elderly are greater in societies where the extended family is a prevalent household unit, and that both are undermined by modernization. Information on 
elderly patterns of co-residence from more broadly based sources of information, such as census data, has been unvailable. Published census data may provide some tabulation of household characteristics based on age of the household head, but they do not provide information on living arrangements of the elderly per se (Martin 1987). Generally-speaking, micro data files created from sampling of the census records in LDCs are rare, or are not accessible to researchers.

Two recent studies reflect current efforts to expand the basis of generalizations by making use of data from large-scale household surveys. Martin (1989) uses a 1984 WHO-sponsored survey on the health of the elderly in four Asian countries to examine how a number of alternative living arrangements (i.e., living alone, with spouse only, with children, or with other relatives only) are related to demographic availability of spouse and children, socio-economic conditions, and cultural status. Although the samples from each country are not necessarily nationally representative, they reflect a broader spectrum of the population than a community study. DeVos (1990) makes innovative use of the 1976 World Fertility Survey from six Latin American countries to compare demographic determinants of extended family living of the elderly. Drawing on nationally representative sets of household data obtained from screening interviews conducted for the fertility survey, she is able to reconstruct the composition of the household and describe the relationship of extended family living to a variety of demographic characteristics of older individuals, including their age, gender, marital status, and urban-rural residence.

Both Martin and DeVos use logit regression techniques for assessing living arrangements. In contrast to linear or ordinary least squares (OLS) regression, logit regression is based on the logarithmic transformation of a multiplicative model in which the underlying relationship between a categorical dependent variable and a set of independent variables or determinants is assumed to be nonlinear (see Aldrich and Nelson 1984). In the studies by Martin and DeVos the dependent variable represents the likelihood of alternative living arrangements as a log odds ratio, as in the log of the odds of living in an extended versus a non-extended family household. Although the multiplicative nature of the underlying model makes the results from this type of analysis more difficult to translate for a broad audience, logit analytic procedures are technically more appropriate than OLS in the analysis of discrete or categorical dependent variables.

Logit and OLS regressions, however, focus on questions of propensities toward a particular type of living arrangement while ignoring the importance of compositional factors in determining both the overall proportion of elderly with a particular living arrangement and the nature of the difference in proportions between populations or subgroups. Additionally, the data from many developing countries limit the researcher's ability to fully exploit the multivariate capabilities of logit analysis. Available data, for instance, may include only simple household rosters indicating the age, gender, and marital status of household members along with their relationship to the household head. Given 
these circumstances, a simpler demographic decomposition may be an informative tool for the elementary descriptive and comparative analysis which is initially needed.

\section{DECOMPOSITION OF LIVING ARRANGEMENTS}

The decomposition is an accounting tool used to disaggregate a social indicator into a set of demographic components. These components typically include compositional characteristics or weights and a set of composition-specific rates or propensities. The decomposition of differences between groups provides a method for comparative analysis. An essential step in identifying potential policy implications of a wide variety of social indicators is the ability to distinguish the extent to which population or group differences arise from differences in compositional features of a population as opposed to underlying sets of rates or propensities.

The utility of the decomposition depends on identifying components which are relevant to the social indicator being investigated. A social welfare perspective which focuses on the needs of a growing elderly population motivates much of the demographic and gerontological research which deals with developing countries. As noted earlier, the family is often seen as the principal source of social support in the face of life course changes. Thus, increased dependency on the family with age is seen as resulting from an increase in the likelihood of health limitations and a diminished capacity to generate earnings. The extended family is also seen as a mechanism of social support for individuals who are no longer part of a nuclear family as a result, for instance, of widowhood or divorce. Thus age and marital status would seem to be two reasonable indicators of life course changes.

In the decomposition given below, the proportion of a population in any given living arrangement may be expressed as the sum of the product of three components, which include a propensity toward a particular arrangement (e.g., an extended family household, nuclear family, living alone, etc.), the marital distribution of the population by age, and the age distribution of the population:

$$
P=\sum_{i=1}^{I} \sum_{j=1}^{J} \frac{L A_{i j}}{M S_{i j}} \cdot \frac{M S_{i j}}{A_{j}} \cdot \frac{A_{j}}{N}
$$

where the $P$ refers to the proportion of the population in a particular living arrangement; the $i$ references marital groups; the $j$ indexes age groups; $L A$ refers to the number of persons with a given living arrangement; $M S$ is a count of persons with a particular marital status; $A$ refers to the number of persons by age; and $N$ represents the total number of persons. The first, or left-most, of the three terms represents the propensity or likelihood of a given living arrangement for each age-marital status group. This propensity is weighted by the marital distribution within age groups and the age distribution of the population 
represented by the second and third terms, respectively, of the above formula.

The decomposition can be expanded to include other components, such as groups of comparative interest within the population. Gender, for instance, is relevant to living arrangements of the elderly in many countries:

$$
P=\sum_{i=1}^{I} \sum_{j=1}^{J} \sum_{k=1}^{K} \frac{L A_{i j k}}{M S_{i j k}} \cdot \frac{M S_{i j k}}{A_{j k}} \cdot \frac{A_{j k}}{N_{k}} \cdot \frac{N_{k}}{N_{t}}
$$

where the subscript $k$ refers to gender and $t$ refers to the total population.

Alternatively, the living arrangements of males and females may be compared by examining the difference in the proportion living in extended family households. Thus,

$$
\begin{aligned}
P_{F}-P_{M} & =\left(\sum_{i=1}^{I} \sum_{j=1}^{J} \frac{L A_{i j F}}{M S_{i j F}} \cdot \frac{M S_{i j F}}{A_{j F}} \cdot \frac{A_{j F}}{N_{F}}\right)- \\
& -\left(\sum_{i=1}^{I} \sum_{j=1}^{I} \frac{L A_{i j M}}{M S_{i j M}} \cdot \frac{M S_{i j M}}{A_{j M}} \cdot \frac{A_{j M}}{N_{M}}\right),
\end{aligned}
$$

where the subscript $F$ refers to the elderly female population and $M$ refers to elderly males.

The practice of identifying the factors which account for group differences by decomposing those differences into components reflecting variation between groups in composition and composition-specific rates is an extension of conventional demographic standardization techniques (Kitagawa 1955). Decomposition of differences has been used in various types of analyses to study a wide range of issues (Winsborough and Dickinson 1970; Althauser and Wigler 1972; O'Connor 1977; Cutright and Smith 1986). The decomposition used in this analysis is similar to that initially proposed by Cutright and Smith (1986:262) in research on the changing incidence of poverty among children.

After substantially rearranging the terms in the above equation, and selecting females as a standard population against which to compare males, the total gender difference may be decomposed into components or "effects" of gender differences in

(a) age composition $(A E)$;

(b) age-specific marital status composition $(M E)$;

(c) propensities toward extended family living within age and marital status categories $(P E)$; and

(d) a set of four interaction terms (AMPE).

In other words, 


$$
P_{F}-P_{M}=A E+M E+P E+A M P E \text {. }
$$

The interactions in the above formulations are treated as a residual. To the extent that the difference components are correlated in a manner which is not offsetting, the interactions will represent a larger proportion of the total difference. This would greatly diminish the utility of the decomposition since interactions represent the proportion of the total difference which cannot be allocated to a single component.

Although the complete algebraic expression for the decomposition appears cumbersome (See Appendix A), the actual calculations may be performed quite simply and directly by using Equation 3 to compare observed with expected values when only one component at a time is changed. The amount of the total difference attributable to each component is the sum of the differences between the observed and expected proportions when that component is changed while the others retain the value of the standard population. The interaction may be easily calculated by summing the major difference components to obtain an expected difference and subtracting this value from the observed difference in living arrangements between males and females to obtain a residual difference equivalent to the total set of interactions.

The analysis which follows will (1) examine the results of the decomposition of living arrangements among Mexican elderly applied separately for males and females; (2) extend the analysis to a decomposition of the gender differences in extended family living arrangements; and (3) discuss the utility and limitations of this type of decomposition strategy for future analysis of the living arrangements of the elderly. This strategy, in essence, begins by examining how age and marital status relate to this social indicator within each gender, and then shows the extent to which the between-gender variation in age and marital status accounts for the gender difference in extended family living arrangements.

\section{DATA}

This decomposition strategy is used to analyze the reportedly high proportion of elderly Mexicans living in households characterized by complex or extended family structures. The data for this analysis are based on information obtained from household screening interviews for the 1982 END, or National Demographic Survey (Consejo Nacional de Poblacion 1982). The survey is a multi-stage, stratified national sample of over 18,000 households, which yields a sample of 5,585 Mexicans age 60 and older. The sample is further divided to permit separate analysis by gender which, after adjusting for sampling design, leaves a sample of 2,703 men and 2,882 women. ${ }^{1}$

Identifying the elderly as those age 60 and older reflects one of several conventional chronological age markers used in research on aging in developing countries (e.g., see Treas and Logue 1986, Kinsella 1988). In the context of the comparatively young population of Mexico, persons age 60 and over constitute the oldest 5 percent of the population. 
The marital status categories used in this analysis include currently married, formerly married, and never-married. Marriage is recognized as including consensual unions as well as those based on civil or religious ceremony. Most of the formerly married in this age range are widows and widowers. While the never-married group is quite small, their life course experience with respect to family formation is different from that of ever-married individuals.

Extended family households are defined by co-residence of kin who are no longer part of the same conjugal unit. Older persons co-residing with married offspring or living in a household which includes relatives other than spouse and unmarried children would be classified as living in an extended family household. Individual data on relationship to head of household were used to reconstruct the types of family connections existing within a household. Similar to DeVos' findings, nearly 55\% of the sample are recorded as living in extended households. Among the women, nearly $62 \%$ live in households with extended kin as compared to $47 \%$ for men.

\section{FINDINGS}

\section{Components of Living Arrangements}

Applications of the decomposition of living arrangements to elderly male and female Mexicans are presented separately in Tables I and II. The components of the decomposition are presented in Columns $\mathrm{A}, \mathrm{B}$ and $\mathrm{C}$ of each table. The propensity toward extended family living, represented in Column A, is calculated as the proportion of persons within each combination of marital status and age categories who live in extended households. For instance, according to Column A of Table I, slightly over $47 \%$ (i.e., 0.473 ) of 60 to 64 year old married women live in extended family households.

The total impact of each of these propensities depends on the relative weight or proportions of elderly who fall into each category. The weight of each category is a function of the age-specific marital distributions and an overall age distribution. In the case of marital status, for instance, Column B of Table I shows that one-half (i.e., 0.499 ) of 60 to 64 year old women are married, another $43 \%$ (i.e., 0.433 ) are widowed, divorced, or separated, and the remaining $7 \%$ (i.e., 0.068) are in the never-married category. The age distribution, irrespective of marital status, is reported in Column C. Nearly one-third (i.e., 0.319) of the elderly women are in the 60 to 64 year age category. The age grouping for single elderly has been truncated at age 70 and older, as opposed to 85 and over, due to the small number of single elderly at older ages.

The product of these three components is reported in Column D. It represents the contribution of each age-marital status category to the total proportion of the population living with extended kin. For example, $7.5 \%$ of all elderly females are married women ages 60 to 64 who live with extended kin. The proportions 
TABLE I

Decomposition of proportion of elderly Mexican females living in extended family household

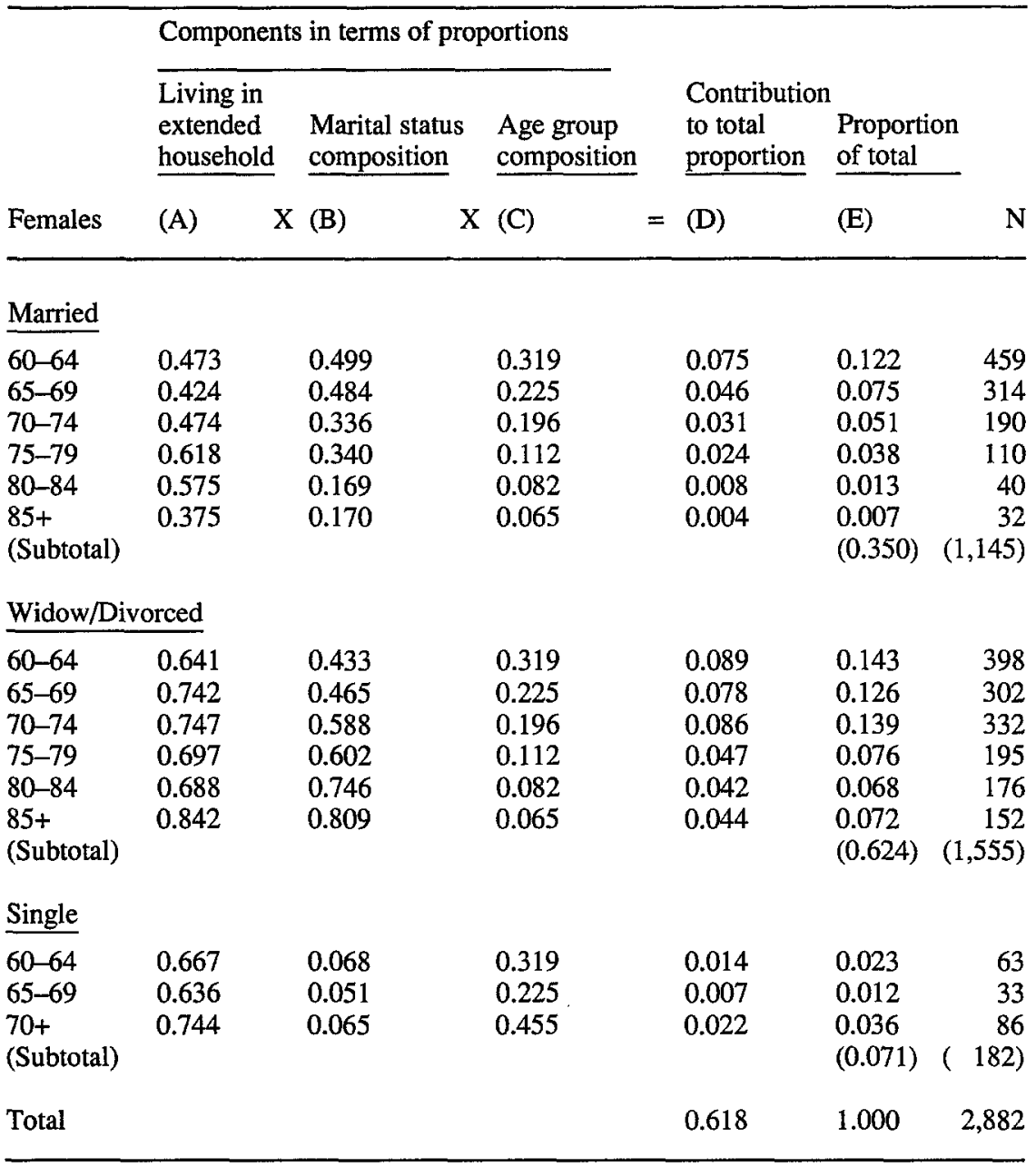

in Column $\mathrm{D}$ are additive, and sum to the proportion of elderly living in extended family households; that is $62 \%$ for females and $47 \%$ for males. The relative contribution of each age-marital status group, expressed as the proportion of the total elderly male or female population living in extended households, is listed in Column E. This column is also additive, and sums to 100 percent, or one. The adjusted sample size of each age-marital status category is listed in the final column of each of these tables. ${ }^{2}$

Focusing first on the propensities in Column A of Tables I and II, it appears that the formerly and never-married males and females in each age category 
have a higher propensity to live with extended kin than those in the currently married group. This observation is consistent with DeVos' finding based on the 1976 WFS data. The consistently high propensities among the formerly married and single groups support the notion that an important function of Mexican households is providing familial integration for persons who may no longer be part of a nuclear family unit.

The propensity toward extended family living arrangements does not show a consistent age pattern within marital status groups for women or men. This is not to say, however, that there are no age differences. Among married women those ages 75 to 84 have higher propensities than younger women, although the overall age pattern is not monotonic. Among married men, those age 80 years of age and older have higher propensities than those found at younger ages, but married men in their seventies have lower propensities for living in extended households than those in their sixties.

In the case of formerly married women those in the oldest age group, age 85 and over, are the most likely to live with extended kin while those in the youngest group are the least likely. The variation among the remaining age groups of formerly married women seems minor when one considers that the proportion living in extended households is consistently high. In contrast to the females, the youngest rather than the oldest of the formerly married males are most likely to be living with extended kin. The bi-modal pattern for formerly married males is difficult to reconcile with the view that age can be simply viewed as an indicator of increasing need for family support. The small sample of single persons, especially for males, cautions against interpreting their reported age differences in the propensity to live with extended kin.

To the degree that there is a tendency to associate extended family living arrangements with a dependency generated by growing older, the observed age differences in this analysis, as in DeVos' (1990) study, do not indicate such a pattern. Yet the observed age differences may suggest a more complex pattern which would take account of the changing role of elderly persons within the household. The bi-modal propensities with respect to age for current and formerly married males, for instance, may be a cross-sectional reflection of a set of life course transitions, the timing of which differs slightly by marital status. In their sixties males may be more likely to be economically active heads of households which include married offspring who work in a family run business or are otherwise economically dependent. Some married offspring set up separate households as they achieve economic independence, thus leading to a slight decline in extended family living as older men move into their late 60 s or early 70 s. Living with married children or other kin increases again as deteriorating health leads a growing proportion of married and widowed men in their late $70 \mathrm{~s}$ and early $80 \mathrm{~s}$ to assume a more dependent role in an extended family household. Of course caution must be maintained in interpreting cross sectional patterns which confound aging and cohort effects. Verification of the life course interpretation suggested above for any cohort would require longitudinal data. The interpretation does serve as a reminder, however, that the factors determin- 
ing the living arrangements of the elderly are likely to include the resources which they bring to a family as well as their need for support. The elderly, particularly males in their $60 \mathrm{~s}$, may be contributing substantial income to a household, while others, particularly elderly females, contribute child care and other domestic services.

The marital status and age group weights become important in understanding the makeup of the elderly living in extended family households. For instance, currently married males constitute over $70 \%$ of the men living with extended kin (Column E of Table II). Given the substantially lower propensities for this type of living arrangement among currently married males as compared to the formerly or never-married, it can be observed from the decomposition that it is the marital status weighting factor (see Column B) which contributes to this result; a large majority of males are still married at older ages. The marital weight and age weights also contribute significantly to the fact that the most dominant category of elderly men living in extended family households is currently married men ages 60-64. They constitute over one-quarter of all elderly men in extended households.

The importance of the age weight can be seen more readily in the case of the females. Nearly two-thirds of all elderly women in extended family households are formerly married. (Column $\mathrm{E}$ of Table I). But because of the age weight factor, the widows ages 60-64 contribute twice as much to the overall proportion as widows age 85 and over, even though the propensity and marital status weight is greater for the older group of widows. Moreover, because of the age weight component, currently married women ages 60-64 who have one of the lowest propensities to live in extended households still constitute a larger percent of elderly females with this living arrangement than the oldest formerly married females.

\section{Decomposition of Gender Differences}

Elderly Mexican females are substantially more likely than elderly males to live in extended family households. The data in Tables I and II indicate that 62 percent of females as compared to 47 percent of males live with extended kin; that is a difference of 15 percentage points. The decompositions in the preceding section demonstrate how a summary indicator of elderly living arrangements is, demographically speaking, dependent on the age and marital status composition or distribution of a population and a set of composition-specific rates or propensities toward living in extended households. By extension, the gender differences in living arrangements may be seen as a function of differences in the age and marital status distributions of older men and women, as well as differences in the underlying propensity toward living with extended kin. Treating one group as a referent or standard for comparison, the decomposition provides a means of describing the relative contribution of each component to the gender differences observed overall for older Mexicans.

Taking the females as a standard population, the row by row data in Table III 
TABLE II

Decomposition of proportion of elderly Mexican males living in extended family household

\begin{tabular}{|c|c|c|c|c|c|c|c|}
\hline \multirow[b]{3}{*}{ Males } & \multicolumn{4}{|c|}{ Components in terms of proportions } & \multirow[b]{2}{*}{$\begin{array}{l}\text { Contribution } \\
\text { to total } \\
\text { proportion }\end{array}$} & \multirow{2}{*}{\multicolumn{2}{|c|}{$\begin{array}{l}\text { Proportion } \\
\text { of total }\end{array}$}} \\
\hline & $\begin{array}{l}\text { Living in } \\
\text { extended } \\
\text { household }\end{array}$ & $\begin{array}{l}\text { Marital status } \\
\text { composition }\end{array}$ & $\begin{array}{l}\text { Age group } \\
\text { composition }\end{array}$ & & & & \\
\hline & (A) & $X(B)$ & $\mathrm{X}(\mathrm{C})$ & $=$ & (D) & (E) & $\mathrm{N}$ \\
\hline \multicolumn{8}{|l|}{ Married } \\
\hline $\begin{array}{l}60-64 \\
65-69 \\
70-74 \\
75-79 \\
80-84 \\
85+ \\
\text { (Subtotal) }\end{array}$ & $\begin{array}{l}0.421 \\
0.454 \\
0.370 \\
0.379 \\
0.495 \\
0.623\end{array}$ & $\begin{array}{l}0.867 \\
0.821 \\
0.818 \\
0.720 \\
0.600 \\
0.589\end{array}$ & $\begin{array}{l}0.336 \\
0.201 \\
0.207 \\
0.155 \\
0.068 \\
0.033\end{array}$ & & $\begin{array}{l}0.123 \\
0.075 \\
0.063 \\
0.042 \\
0.020 \\
0.012\end{array}$ & $\begin{array}{l}0.262 \\
0.160 \\
0.134 \\
0.091 \\
0.043 \\
0.026 \\
(0.717)\end{array}$ & $\begin{array}{r}788 \\
445 \\
457 \\
301 \\
111 \\
53 \\
(2,155)\end{array}$ \\
\hline \multicolumn{8}{|c|}{ Widow/Divorced } \\
\hline $\begin{array}{l}60-64 \\
65-69 \\
70-74 \\
75-79 \\
80-84 \\
85+ \\
\text { (Subtotal) }\end{array}$ & $\begin{array}{l}0.807 \\
0.537 \\
0.651 \\
0.710 \\
0.565 \\
0.676\end{array}$ & $\begin{array}{l}0.091 \\
0.151 \\
0.148 \\
0.256 \\
0.373 \\
0.411\end{array}$ & $\begin{array}{l}0.336 \\
0.201 \\
0.207 \\
0.155 \\
0.068 \\
0.033\end{array}$ & & $\begin{array}{l}0.025 \\
0.016 \\
0.020 \\
0.028 \\
0.014 \\
0.009\end{array}$ & $\begin{array}{l}0.053 \\
0.035 \\
0.043 \\
0.060 \\
0.031 \\
0.020 \\
(0.241)\end{array}$ & $\begin{array}{r}83 \\
82 \\
83 \\
107 \\
69 \\
37 \\
(\quad 461)\end{array}$ \\
\hline \multicolumn{8}{|l|}{ Single } \\
\hline $\begin{array}{l}60-64 \\
65-69 \\
70+ \\
\text { (Subtotal) }\end{array}$ & $\begin{array}{l}0.684 \\
0.667 \\
0.471\end{array}$ & $\begin{array}{l}0.042 \\
0.028 \\
0.027\end{array}$ & $\begin{array}{l}0.336 \\
0.201 \\
0.462\end{array}$ & & $\begin{array}{l}0.010 \\
0.004 \\
0.007\end{array}$ & $\begin{array}{l}0.021 \\
0.008 \\
0.014 \\
(0.043)\end{array}$ & $\begin{array}{r}38 \\
15 \\
34 \\
(\quad 87)\end{array}$ \\
\hline Total & & & & & 0.467 & 1.000 & 2,703 \\
\hline
\end{tabular}

show how much of the gender difference is due to each factor in each agemarital grouping. For example, the column labelled "propensity" shows the magnitude of the gender difference when substituting male propensities and keeping the female marital status and age distributions; the column labelled "marital status" shows the effect of substituting male marital status proportions while fixing the propensity and age distributions to equal those of the females; and the column labelled "age" substitutes male age proportions while relying on the female propensity and marital status distributions. 


\section{TABLE III}

Decomposition of crude gender differences in proportion of older Mexicans living in extended family households with females as the standard population

\begin{tabular}{|c|c|c|c|c|c|c|c|}
\hline & \multicolumn{4}{|c|}{ Difference components } & \multirow[b]{2}{*}{$\begin{array}{l}\text { Expected } \\
\text { difference }\end{array}$} & \multirow[b]{2}{*}{$\begin{array}{l}\text { Actual } \\
\text { difference }\end{array}$} & \multirow[b]{2}{*}{$\begin{array}{l}\text { Residual } \\
\text { interaction }\end{array}$} \\
\hline & Propensi & - Marital & + Age & $=$ & & & \\
\hline \multicolumn{8}{|c|}{ Married } \\
\hline $\begin{array}{l}60-64 \\
65-69 \\
70-74 \\
75-79 \\
80-84 \\
85+\end{array}$ & $\begin{array}{r}0.008 \\
-0.003 \\
0.007 \\
0.009 \\
0.001 \\
-0.003\end{array}$ & $\begin{array}{l}-0.056 \\
-0.032 \\
-0.045 \\
-0.026 \\
-0.020 \\
-0.010\end{array}$ & $\begin{array}{r}-0.004 \\
0.005 \\
-0.002 \\
-0.009 \\
0.001 \\
0.002\end{array}$ & & $\begin{array}{l}-0.051 \\
-0.030 \\
-0.040 \\
-0.026 \\
-0.018 \\
-0.011\end{array}$ & $\begin{array}{l}-0.047 \\
-0.029 \\
-0.031 \\
-0.019 \\
-0.012 \\
-0.008\end{array}$ & $\begin{array}{l}0.004 \\
0.002 \\
0.008 \\
0.007 \\
0.006 \\
0.003\end{array}$ \\
\hline \multicolumn{8}{|c|}{ Widow/Divorced } \\
\hline $\begin{array}{l}60-64 \\
65-69 \\
70-74 \\
75-79 \\
80-84 \\
85+\end{array}$ & $\begin{array}{r}-0.023 \\
0.021 \\
0.011 \\
-0.001 \\
0.008 \\
0.009\end{array}$ & $\begin{array}{l}0.070 \\
0.052 \\
0.064 \\
0.027 \\
0.021 \\
0.022\end{array}$ & $\begin{array}{r}-0.005 \\
0.008 \\
-0.005 \\
-0.018 \\
0.007 \\
0.022\end{array}$ & & $\begin{array}{l}0.042 \\
0.082 \\
0.071 \\
0.008 \\
0.036 \\
0.052\end{array}$ & $\begin{array}{l}0.064 \\
0.061 \\
0.066 \\
0.019 \\
0.028 \\
0.035\end{array}$ & $\begin{array}{r}0.022 \\
-0.021 \\
-0.005 \\
0.011 \\
-0.008 \\
-0.017\end{array}$ \\
\hline \multicolumn{8}{|l|}{ Single } \\
\hline $\begin{array}{l}60-64 \\
65-69 \\
70+\end{array}$ & $\begin{array}{r}-0.000 \\
-0.000 \\
0.008\end{array}$ & $\begin{array}{l}0.006 \\
0.003 \\
0.013\end{array}$ & $\begin{array}{r}-0.001 \\
0.001 \\
-0.000\end{array}$ & & $\begin{array}{l}0.004 \\
0.004 \\
0.021\end{array}$ & $\begin{array}{l}0.005 \\
0.004 \\
0.016\end{array}$ & $\begin{array}{r}0.000 \\
-0.000 \\
-0.005\end{array}$ \\
\hline Total & 0.051 & 0.089 & 0.003 & & 0.143 & 0.151 & 0.008 \\
\hline
\end{tabular}

The positive elements under each of these components represent a contribution toward the greater proportion of older females living in extended households as compared to males. Negative elements represent the reverse. They occur in the propensity component whenever the composition-specific tendency toward an extended household living arrangement is greater for men than for women. Negative values appear in the columns of the age and marital status components whenever the proportion of males in those categories is greater than the proportion of females.

These elements are additive both across components for each row or age-marital status category, and within columns for each component of the gender difference. The sum of the components across rows provides an expected difference. An interaction term represents the joint effect of the compositional characteristics which cannot be readily allocated. It is calculated in Table III as a residual by subtracting the actual gender difference from the expected difference. 
The line labelled "Total" at the bottom of Table III indicates the amount of difference attributable to each of the components, the total expected and actual differences and the cumulative residual interaction. The marital distribution of males relative to females accounts for 8.9 percentage points of the total gender difference in living arrangements, which is well over half of the total difference. Differences between males and females in the composition-specific propensities account for another 5.1 percentage points. Difference in age distributions has only a minor effect as does the interaction or joint compositional term. The latter is particularly important for this type of decomposition, since a large interaction effect would make it difficult to allocate the gender differences in living arrangements into three independent difference components. ${ }^{3}$

The overall difference in the proportion of elderly males and females living with extended kin is, from a demographic perspective, primarily a function of differences in marital status, and secondarily a result of differences in agemarital status specific rates or propensities for this living arrangement. Among both males and females, the formerly and never married elderly are more likely to live with extended kin than currently married. The impact of marital status reflects the fact that in comparison to elderly women, a much smaller proportion of elderly men are widowed, separated, divorced or single. For instance, less than $10 \%$ of males ages $60-64$ are formerly married compared to over $40 \%$ of females. And even among those 85 and older, the proportion of females who are formerly married is twice that of males (i.e., $81 \%$ vs. $41 \%$ ). If men had the same marital distribution as females of the same age the expected gender difference for living with extended kin would be reduced from 15 percent to 6 percent. Although marital status is not directly manipulated in policy terms, age-specific gender differences in marital status could shift as a result of other social changes. Increasing social status of women vis-à-vis men, for instance, might reduce the age gap between spouses. If women were to postpone marriage to improve their own life chances in terms of education and careers, while men retained the same age at marriage pattern, then one would expect women to be marrying men more comparable in age. This could result in more women being married at older ages even if there were no change in life expectancy of males and females.

\section{DISCUSSION}

The decomposition procedures presented in this paper are analytic tools which may contribute to the accumulation of knowledge concerning the population of the elderly in developing countries. Demographic changes are prompting growing interest in examining the social status and condition of the elderly of which living arrangements is seen as one indicator. Current empirical knowledge of elderly living arrangements is limited and population-based analysis and monitoring of family living arrangements are likely to require innovative use of existing data resources. In this context, the utility of demographic decomposition analysis can be seen in several respects. 
First, the decomposition expands the usefulness of a social indicator by disaggregating it into its demographic components. The components are presented in a manner which facilitates integrating two types of information that would otherwise be obscured; namely, the relationship among the demographic components of the indicator and the demographic profile of the elderly who live with extended kin. For example, the earlier analysis revealed that despite a greater tendency for formerly as compared to currently married males to live with extended kin, currently married men constitute almost three-quarters of the elderly living with extended kin. From the decomposition presented in Table II it is easy to see that the predominance of currently married males in extended households results from the high proportion of elderly males who are married.

Second, the analytic utility of this tool is extended to comparative research through the use of standardized decomposition of differences between groups. From the standpoint of parsimony, this permits one to simultaneously summarize the impact of both population composition and propensities on observed differences. These insights are not directly obtained from a single logit regression or a loglinear model.

Third, although the example presented in this paper is based on subgroups within a population, decomposition of differences in living arrangements may be conducted cross-nationally or over time when the definition or taxonomy of households is sufficiently similar. Cross-national comparisons would reveal the extent to which observed differences in elderly living arrangements are a function of age, gender, or marital status distributions, or of differences in propensities toward a particular household arrangement. If data were available for two time points the decomposition of period differences would provide a demographic accounting of observed changes in elderly living situations. If no change is observed in the indicator, the decomposition would help reveal whether stability were dependent on compensating shifts among the various components. Drawing conclusions about life course or age-related changes is problematic with data from one or even two periods, particularly in countries like Mexico which are undergoing significant socio-demographic change. The availability of data from multiple time points would create the possibility for a repeated cross-sectional study design in which cohorts could be traced over time.

Fourth, the relative simplicity of the technique facilitates communication to a broad audience of professionals with varying statistical expertise. Components of the decomposition are expressed in terms of proportions. The analytic procedures rely on algebraic manipulations which are easily carried out on any micro-computer spreadsheet.

Fifth, the technique makes effective use of large sample household surveys which may have only limited information on the elderly. The Agency for International Development (AID) sponsored Demographic Health Surveys, which have recently been completed in a number of developing countries, have a household component from which living arrangements could be constructed. If compared with data from the household components of the earlier World 
Fertility Surveys, the two time points would provide a basis for analyzing stability and change in the living arrangements of elderly in numerous developing countries. Additional data sources might also include labor force or income and expenditure surveys which include information on household members regarding their family ties.

This analytic tool also has important limitations that need to be recognized. Demographic decompositions are a form of tabular analysis which require large sample surveys in order to obtain sufficient data for each cell of the table. Even in large samples, the technique may have to be adjusted to accommodate relatively rare conditions, such as in the case of older never-married individuals in the present analysis. Although the decomposition may be expended to include other dimensions (e.g., urban-rural residence) the data quickly become sparse. The more variables that are added, the more cumbersome it becomes to summarize the results.

As noted earlier, the demographic decomposition of differences is an extension of standardization techniques used in demography. In recent years these standardization procedures have been criticized for being sensitive to the choice of standards and for not being linked to a general statistical framework. As a consequence of the latter, the standardization technique does not provide for a statistical test of group differences in rates. Clogg and his colleagues (Clogg 1978; Clogg and Eliason 1988) and other (Xie 1989) have proposed a variety of $\log$ linear modelling techniques which control for compositional differences and test for significant differences in adjusted rates between groups. There is no direct method, however, for carrying out decompositions from these techniques (Liao 1989). ${ }^{4}$ Researchers interested in decomposition of differences in social indicators tend to rely on traditional standardization (Ross and Sawhill 1975; Wojtkiewicz, McClanahan, and Garfinkel 1990).

In light of the current lack of empirical knowledge about elderly populations and the limitations of available data resources, the demographic decomposition described in this paper offers a convenient tool for proceeding with descriptive and exploratory analysis of the living arrangements of the elderly. Its application to comparative analyses over time or cross-nationally is straightforward and can be readily communicated to a broad audience. Acquiring the basic knowledge afforded by this technique would seem to be a useful step before proceeding with elaborate models or projections of living arrangements of the elderly.

\section{ACKNOWLEDGEMENTS}

Research for this paper was supported in part by a National Institute on Aging (NIA) Training Grant (T32 AG00151) and a NIA research grant, "Aging in Asia" (R37 AG07637). The authors gratefully acknowledge the Consejo Nacional de Población (CONAPO) of Mexico for permission to use the 1982 Encuesta Nacional Demográfica. 


\section{APPENDIX A}

By substantially rearranging the terms on the left side of the Equation 3, and using the females as a standard population against which to compare males, the decomposition is expressed in the following manner:

(5) $P_{i j F}-P_{i j M}=$

(5a) an age effect

$\sum_{i=1}^{I} \sum_{j=1}^{J} \frac{L A_{i j F}}{M S_{i j F}} \cdot \frac{M S_{i j F}}{A_{j F}} \cdot\left(\frac{A_{j F}}{N_{F}}-\frac{A_{j M}}{N_{M}}\right)+$

(5b) a marital status effect

$\sum_{i=1}^{I} \sum_{j=1}^{J} \frac{L A_{i j F}}{M S_{i j F}} \cdot\left(\frac{M S_{i j F}}{A_{j F}}-\frac{M S_{i j M}}{A_{j M}}\right) \cdot \frac{A_{j F}}{N_{F}}+$

(5c) a propensity effect

$\sum_{i=1}^{I} \sum_{j=1}^{J}\left(\frac{L A_{i j F}}{M S_{i j F}}-\frac{L A_{i j M}}{M S_{i j M}}\right) \cdot \frac{M S_{i j F}}{A_{j F}} \cdot \frac{A_{j F}}{N_{F}}+$

(5d) a residual sum of interactions

$$
\begin{aligned}
& \sum_{i=1}^{I} \sum_{j=1}^{J} \frac{L A_{i j F}}{M S_{i j F}} \cdot\left(\frac{M S_{i j F}}{A_{j F}}-\frac{M S_{i j M}}{A_{j M}}\right) \cdot\left(\frac{A_{j F}}{N_{F}}-\frac{A_{j M}}{N_{M}}\right)+ \\
& \sum_{i=1}^{I} \sum_{j=1}^{J}\left(\frac{L A_{i j F}}{M S_{i j F}}-\frac{L A_{i j M}}{M S_{i j M}}\right) \cdot \frac{M S_{i j F}}{A_{j F}} \cdot\left(\frac{A_{j F}}{N_{F}}-\frac{A_{j M}}{N_{M}}\right) \\
& \sum_{i=1}^{I} \sum_{j=1}^{J}\left(\frac{L A_{i j F}}{M S_{i j F}}-\frac{L A_{i j M}}{M S_{i j M}}\right) \cdot\left(\frac{M S_{i j F}}{A_{j F}}-\frac{M S_{i j M}}{A_{j M}}\right) \cdot \frac{A_{j F}}{N_{F}}+ \\
& \sum_{i=1}^{I} \sum_{j=1}^{J}\left(\frac{L A_{i j F}}{M S_{i j F}}-\frac{L A_{i j M}}{M S_{i j M}}\right) \cdot\left(\frac{M S_{i j F}}{A_{j F}}-\frac{M S_{i j M}}{A_{j M}}\right) \cdot\left(\frac{A_{j F}}{N_{F}}-\frac{A_{j M}}{N_{M}}\right)
\end{aligned}
$$




\section{NOTES}

* An earlier version of this paper was presented at the 42nd Annual Meetings of the Gerontological Society of America held in Minneapolis, Minnesota, November 17-21, 1989.

1 Since the 1982 END is based on a stratified sampling design in which the probability of inclusion differs across geographic strata, weights provided by CONAPO are used to adjust for the sampling design while holding the total sample size constant.

2 The adjusted sample size of each age-marital status category reflects the differential weight assigned by geographic location to each case on the basis of the sampling design. The total adjusted sample is constrained to equal the actual sample size.

${ }^{3}$ Some analysts have proposed alternative allocations of the interaction term to the various components (e.g., Das Gupta 1978), but this does not obviate the point that large interactions indicate a lack of independence of the different components.

${ }^{4}$ Liao (1989) recently proposed an indirect method for integrating rate standardization methods based on log linear analysis into a decomposition through the use of a system of simultaneous linear equations. The application and utility of this technique to the study of elderly living arrangements deserves further consideration in future research.

\section{REFERENCES}

Aldrich, J.H. and F.D. Nelson 1984 Linear Probability, Logit, and Probit Models. Beverly Hills: Sage Publications.

Althauser, R.P. and M. Wigler 1972 Standardization and component analysis. Sociological Methods \& Research 1:97-135.

Bianchi, S.M. 1981 Household Composition and Racial Inequality. New Brunswick, N.J.: Rutgers University Press.

Binstock, R.H., W.Chow, and J.H. Schulz, eds. 1982 International Perspectives on Aging: Population and Policy Challenges. UNFPA Policy Development Studies No. 7. New York: United Nations.

Bongaarts, J. 1983 The Formal Demography of Families and Households: An Overview. IUSSP Newsletter No. 17:27-42.

Clogg, C.C. 1978 Adjustment of Rates Using Multiplicative Models. Demography 15:523-539.

Clogg, C. and S.R. Eliason 1988 A Flexible Procedure for Adjusting Rates and Proportions, Including Statistical Methods for Group Comparisons. American Sociological Review 53:267-283.

Consejo Nacional de Poblacion 1982 Enuesta Nacional Demografica, Mexico.

Cowgill, D.O. 1986 Aging Around the World. Belmont, California: Wadsworth Publishing Company.

Cowgill, D.O. and L.D. Holmes, eds. 1972 Aging and Modernization. New York: Appleton-Century Crofts.

Cutright, P. and H.L. Smith 1986 Declining Family Size and the Number of Children in Poor Families in the United States: 1964-1983. Social Science Research 15:256-268.

Das Gupta, P. 1978 A General Method for Decomposing a Difference Between Two Rates into Several Components. Demography 15:99-112.

DeVos, S. 1987 Latin American Households in Comparative Perspective. Population Studies 41:501-517.

DeVos, S. 1990 Extended Family Living Among Older People in Six Latin American Countries. Journals of Gerontology 45:S87-S94.

Giele, J.Z. 1982 Family and Social Networks. In International Perspectives on Aging: Population and Policy Challenges. R.H. Binstock, W. Chow, and J.H. Schulz, eds. Pp. 41-74. UNFPA Policy Development Studies No. 7 New York: United Nations. 
Kertzer, D.I. 1986 A Life Course Approach to Coresidence. Current Perspectives on Aging and the Life Cycle, Vol. 2:1-22. Greenwich, Connecticut: JAI Press, Inc.

Kinsella, K. 1988 Aging in the Third World. International Population Reports Series P-95, No. 79. Washington, D.C.: U.S. Bureau of the Census, U.S. Government Printing Office.

Kitagawa, E.M. 1955 Components of a Difference Between Two Rates. Journal of the American Statistical Association 50:1168-1194.

Liao, T.F. 1989 A Flexible Approach for the Decomposition of Rate Differences. Demography 26:717-726.

Martin, L.G. 1987 Census Data for Studying Elderly Populations. Asia-Pacific Population Journal 2:69-82.

Martin, L.G. 1989 Living Arrangements of the Elderly in Fiji, Korea, Malaysia, and the Philippines. Demography 26:627-644.

O'Connor, J.F. 1977 A Logarithmic Technique for Decomposing Change. Sociological Methods \& Research 6(1):91-102.

Ross, H.L. and I.V. Sawhill 1975 Time of Transition: The Growth of Families Headed by Women. Washington, D.C.: The Urban Institute.

Sweet, J. 1978 Indicators of Family and Household Structure of Racial and Ethnic Minorities. In The Demography of Racial and Ethnic Groups. F.D. Bean and W.P. Frisbie, eds. Pp. 221-260. New York: Academic Press.

Tout, K. 1989 Aging in Developing Countries. Oxford: Oxford University Press.

Treas, J. and B. Logue 1986 Economic Development and the Older Population. Population and Development Review 12:645-673.

Wall, R., J. Robin and P. Laslett, eds. 1983 Family Forms in Historic Europe. Cambridge: Cambridge University Press.

Winsborough, H.H. and P. Dickinson 1970 Components of Negro White Income Differences. American Statistical Association Proceedings of the Social Statistics Section, Washington, D.C.

Wojtkiewicz, R.A., S. McClanahan, and I. Garfinkel 1990 The Growth of Families Headed by Women: 1950-1980. Demography 27:19-30.

Wolf, D.A. 1984 Kin Availability and the Living Arrangements of Older Women. Social Science Research 13:72-89.

Wolf, D.A. and B.J. Soldo 1988 Household Composition Choices of Older Unmarried Women. Demography 25:387-403.

Xie, Y. 1989 An Alternative Purging Method: Controlling the Composition-Dependent Interaction in an Analysis of Rates. Demography 26:711-716.

\section{Population Studies Center}

University of Michigan

1225 South University Avenue

Ann Arbor, Michigan 48104-2590, U.S.A. 